\title{
Tobacco mosaic virus-templated hierarchical Ni/NiO with high electrochemical charge storage performances
}

Sangwook Chu ${ }^{\text {a, b }}$, Konstantinos Gerasopoulos ${ }^{\text {, }}$, and Reza Ghodssi ${ }^{\text {a, b, * }}$

${ }^{a}$ Department of Electrical and Computer Engineering, University of Maryland, College Park, MD 20742, USA.

${ }^{\mathrm{b}}$ Institute of Systems Research, University of Maryland, College Park, MD 20742, USA

* Corresponding Author

E-mail: ghodssi@umd.edu; Phone: +1 301-405-8158

\begin{abstract}
Three-dimesional hierarchical electrodes exhibiting multi-dimensional geometries provide exceptional advantages for advanced energy storage performance. In this work, we report the fabrication and characterization of biotemplated hierarchical-Ni/NiO electrodes enabled by thermal oxidation of electroless Ni-coated Tobacco mosaic viruses (TMVs) self-assembled on Au-coated Si micropillar arrays. Uniform NiO formation on the metallized TMV nanoscaffolds is characterized by XPS and STEM-EELS analysis and the electrochemical performance was characterized in $2 \mathrm{M} \mathrm{KOH}$ solution. The hierarchical$\mathrm{Ni} / \mathrm{NiO}$ show a 3.3 and 32.6 times increase in areal capacity $\left(81.4 \mu \mathrm{Ah} \mathrm{cm}^{-2}\right)$ compared to solely nanostructured $\left(24.3 \mu \mathrm{Ah} \mathrm{cm}^{-2}\right)$ and planar electrodes $\left(2.5 \mu \mathrm{Ah} \mathrm{cm}^{-2}\right)$, respectively. The NiO electrodes show interesting capacity increase phenomenon during the initial activation cycles. Based on our experimental analysis, it is attributed to both an increase in active surface area/mesoporosity and $\mathrm{NiO}$ content during the initial charge/discharge cycles, and the increase has dependence on electrode geometry. The hierarhical-Ni/NiO electrode exhibit excellent cycle stability up to 1500 charge/discharge cycles at $2 \mathrm{~mA} \mathrm{~cm}^{-2}$ with no capacity fading. Based on the results, the hierarchical-Ni/NiO is a promising candidate for advanced electrochemical energy storage devices.
\end{abstract}

\section{Keywords}

Biological templates, nickel oxide, electrochemical charge storage, hierarchical electrodes. 


\section{Introduction}

Electrochemical charge storage (ECS) devices including Li-ion batteries and electrochemical capacitors have received significant attention due to the rapidly growing electronics market (e.g. electric vehicles, portable electronics, etc.) requiring charge storage devices with both high power and energy densities [1]. Particularly, the recent development of faradaic electrode materials in micro/nanoscale geometries is one of the most significant advancements, where the high surface area-to-volume ratio coupled with facile charge storage kinetics are essential for reaching the desired performance criteria [2,3].

Various transition metal oxides $\left(\mathrm{Co}_{3} \mathrm{O}_{4}, \mathrm{MnO}_{2}, \mathrm{NiO}\right.$, etc. $)$ and their composites are very attractive candidates for the high performance ECS electrodes owe to their excellent faradaic charge storage characteristics at economic costs. Among the potential candidates, $\mathrm{NiO}$ brings great interest with its excellent "battery-like" charge storage behavior exhibiting very high theoretical gravimetric capacities of $359 \mathrm{mAh} \mathrm{g}^{-1}$ and $718 \mathrm{mAh} \mathrm{g}^{-1}$ in alkaline $\left(\mathrm{NiO}+\mathrm{OH}^{-} \leftrightarrow \mathrm{NiOOH}+\mathrm{e}^{-}\right.$, in $0-0.5 \mathrm{~V}$ vs. $\left.\mathrm{Ag} / \mathrm{AgCl}\right)$ and $\mathrm{Li}^{+}$ $\left(\mathrm{NiO}+2 \mathrm{Li}^{+}+2 \mathrm{e}^{-} \rightarrow \mathrm{Ni}+\mathrm{Li}_{2} \mathrm{O}\right.$, in $0.005-3 \mathrm{~V}$ vs. Li-foil) electrolytes, respectively [4,5]. For this reason, many researchers have recently investigated the use of $\mathrm{NiO}$ as electrode materials for both electrochemical capacitors and Li-ion batteries. Luan et al. [6] have demonstrated an asymmetric supercapacitor device combining $\mathrm{NiO}$ nanoflakes (cathode) and reduced graphene oxide (anode) grown on carbon cloth and $\mathrm{Ni}$ foam, respectively. The asymmetric configuration allowed expansion of the operation potential window up to $1.7 \mathrm{~V}$ in alkaline electrolyte $(1 \mathrm{M} \mathrm{KOH})$ with remarkable areal

capacitance $\left(248 \mathrm{mF} \mathrm{cm}^{-2}\right.$ at $1 \mathrm{~mA} \mathrm{~cm}^{-2}$ ) benefiting from the high surface area $\mathrm{NiO}$ electrodes. Also, nanoscale $\mathrm{NiO}$ has been investigated as an anode material for $\mathrm{Li}$-ion batteries in the last years for its high theoretical Li capacity compared to conventional graphite anode materials. Characterized in half-cell configuration (vs. Li-foil), many articles have reported reversible gravimetric energy density reaching or going above its theoretical limit at $1 \mathrm{C}$ current rate, representing more than a 2 -fold increase compared to 
conventional carbon-based anode materials $[5,7,8]$. It should be noted here that the charge capacities in previous ECS $\mathrm{NiO}$ reports have been evaluated in different units depending on their targeted ECS systems ( $\mathrm{F} \mathrm{g}^{-1}$ or $\mathrm{F} \mathrm{cm}^{-2}$ for electrochemical capacitors, and $\mathrm{mAh} \mathrm{g}^{-1}$ or $\mathrm{mAh}^{-2}$ for batteries). Considering a recent report by Brousse et al. [9], suggesting classification criteria for proper categorization/characterization of electrode materials for electrochemical capacitors, the charge capacities in this work are presented in $\mu \mathrm{Ah} \mathrm{cm}^{-2}$ considering the NiO's "battery-like" electrochemical signature.

Various methods for fabrication/synthesis of micro/nanoscale $\mathrm{NiO}$ electrodes have been reported. In general, $\mathrm{NiO}$ was either directly synthesized on $\mathrm{Ni}$ or other current collectors, or prepared in nanoparticle forms, which requires mixing with polymer binders and conductive additives [5,7,10-15]. Comparing the two methods, the latter suffers from lack in electrical connectivity between the current collector and the active material while the direct synthesis methods ensure continuous connection between the two electrode components critical for efficient charge adsorption/transfer mechanism at the electrolyte/electrode interface. Using this approach, Wang et al. [14] achieved 99\% of NiO's theoretical gravimetric capacity (355 $\mathrm{mAh} \mathrm{g}^{-1}$ in $2 \mathrm{M} \mathrm{KOH}$ ) by annealing $\mathrm{Ni}(\mathrm{OH})_{2}$ precursors that were directly precipitated on Ni foam. The uniform nanoscale active layer coating over the current collector is believed to be one of the key factors in achieving high NiO-based ECS performances, compensating for the low electrical conductivity of the $\mathrm{NiO}[13,14,16]$.

In the past decade, our group and collaborators have reported the use of genetically modified TMVs as nanostructured templates for various ECS devices. TMV is a high aspect ratio cylindrical plant virus (300 $\mathrm{nm}$ in length, $18 \mathrm{~nm}$ in diameter), and its surface can be genetically modified with cysteine groups resulting in enhanced self-assembly (Au-thiol binding) and uniform electroless Ni-coating properties [17]. Integrating the TMV process with microfabrication techniques, Ni-coated TMVs (TMV/Ni) have served as nanoscale three-dimensional current collectors for Li-ion battery and supercapacitor electrodes [18- 
21]. These nanoelectrode architectures have relied on additional thin-film deposition steps for the formation of uniform ECS layers on the TMV/Ni.

In this work, we present the fabrication and characterization of hierarchical-Ni/NiO electrodes leveraging the electroless TMV Ni-coating process. The $\mathrm{NiO}$ is formed directly on the TMV/Ni nanorods via a simple annealing process. This eliminates the need for any additional active material deposition steps and simplifies the TMV micro/nanofabrication process for high-performance ECS devices. The hierarchical electrode structure is realized by combining the TMVs with $\mathrm{Si}$ micropillar arrays. Electrochemical performance characterization results are presented with a strong emphasis on their significant charge capacity increase behavior during the initial charge/discharge cycles.

\section{Experimental}

The detailed purification protocol for cysteine-modified TMVs and the chemicals used for electroless Nimetallization can be found in previous report [17].

\subsection{TMV/Ni-core NiO-shell electrodes via thermal oxidation}

The thermal annealing process for formation of NiO-shell layer on TMV/Ni-core surface is characterized using X-ray photoelectron spectroscopy (XPS, Kratos AXIS 165 spectroscopy), and transmission electron microscopy (JEM 2100 FEG-TEM) with scanning TEM (STEM) and electron energy loss spectroscopy (EELS) capabilities. TMV/Ni electrode samples are prepared following the procedure described in our previous work [17]. $1 \times 1 \mathrm{~cm}^{2}$ Au-coated planar Si electrodes are immersed in TMV solution $\left(0.2 \mathrm{mg} \mathrm{ml}^{-1}\right.$ in $0.1 \mathrm{M}$ phosphate buffer solution $(\mathrm{pH} 7)$ ), and incubated overnight at room temperature for selfassembly of TMVs onto Au surface through thiol-Au binding. This is followed by the electroless-Ni metallization process to yield robust nanostructured $\mathrm{Ni}$ electrodes. As-prepared electroless $\mathrm{Ni}$ on TMV is metallic with residual oxides $(\mathrm{NiO})$ and hydroxides $\left(\mathrm{Ni}(\mathrm{OH})_{2}\right)$ on its surface [17]. Thermal oxidation at high temperatures can result in removal of $\mathrm{Ni}(\mathrm{OH})_{2}$ and increase in the $\mathrm{NiO}$ content as illustrated in Fig. 1. 
For process optimization, TMV/Ni electrodes are annealed at four different temperatures - room temperature, $200{ }^{\circ} \mathrm{C}, 300{ }^{\circ} \mathrm{C}$, and $400{ }^{\circ} \mathrm{C}$ - in an air-filled box furnace. The temperatures were ramped at a rate of $5^{\circ} \mathrm{C} \min ^{-1}$ to the target temperatures and spontaneously cooled down to the room temperature after a 2 hour annealing step. XPS analysis allowed analysis of the $\mathrm{NiO}$ formation on/into the Ni surface at the different temperatures, and the STEM/EELS analysis is carried out to confirm the uniform formation of $\mathrm{NiO}$ (shell) layer over the TMV/Ni (core) nanorod electrodes.

\subsection{Fabrication of hierarchical-Ni/NiO electrodes}

The hierarchical-Ni/NiO electrodes are fabricated by combining the TMV/Ni/NiO nanorods with Ausputtered Si micropillar arrays as shown in Fig. 2a. The micropillar arrays are fabricated using deepreactive-ion-etching (DRIE, STS Deep Reactive Ion Etcher) of Si wafers with negative photoresist (AZ5214) etch masks patterned via photolithography. The Si micropillars are then passivated with $500 \mathrm{~nm}$ $\mathrm{Si}_{3} \mathrm{~N}_{4}$ deposited by plasma enhanced chemical vapor deposition (PECVD, Oxford Plasmalab System 100) at $300^{\circ} \mathrm{C}$. Sputtering (Model AJA International, ATC 1800-V) of Ti $(30 \mathrm{~nm}) / \mathrm{Au}(200 \mathrm{~nm})$ is followed as a current collector and the self-assembly process. TMV self-assembly on dense microstructures has shown limitations due to restricted structural wetting [22]. Isopropyl alcohol (IPA) wetting of the electrodes prior to the TMV self-assembly step improves the structural wettability, thereby achieving excellent TMV coverage over the high aspect ratio micropillar surfaces (10:1 for pillar and 5:1 for spacing). Such high-aspect-ratio geometries are critical for increasing the surface area; the area enhancement factor depends on density and height of the pillar arrays (Fig. 2b). After the electroless-Ni metallization of the TMV self-assembled hierarchical structure, the resulting electrodes are annealed at high temperatures to create hierarchical $\mathrm{Ni} / \mathrm{NiO}$ electrodes. The final electrode structures are examined by scanning electron microscopy (SEM, Hitachi S-3400).

\subsection{Electrochemical performance characterization and analysis}


All electrochemical characterization is performed using a potentiostat (Biologic VSP-300) with a threeelectrode-system (working: $\mathrm{NiO}$ electrodes, counter: Pt-foil $\left(1 \times 1 \mathrm{~cm}^{2}\right)$, reference: $\mathrm{Ag} / \mathrm{AgCl}$ in $\left.1 \mathrm{M} \mathrm{KCl}\right)$ immersed in $2 \mathrm{M} \mathrm{KOH}$ aqueous electrolyte $\left(\mathrm{NiO}+\mathrm{OH}^{-} \leftrightarrow \mathrm{NiOOH}+\mathrm{e}^{-}\right)$. Optimal annealing temperature was characterized by testing nanostructured-Ni/NiO (TMV/Ni/NiO on planar $\mathrm{Au}$ substrate) electrodes in galvanostatic charge/discharge cycles at $2 \mathrm{~mA} \mathrm{~cm}^{-2}$, and the reversible charge storage behavior was characterized in cyclic voltammetry with a range of scan rates $\left(10-100 \mathrm{mV} \mathrm{s}^{-1}\right)$. All electrochemical testing was performed within the $0-0.5 \mathrm{~V}$ potential window vs. $\mathrm{Ag} / \mathrm{AgCl}$ reference electrode. The electrochemical performance of the hierarchical-Ni/NiO electrodes is evaluated in comparison with nanostructured- and planar-Ni/NiO electrodes (the planar-Ni/NiO electrodes were prepared by electroless-Ni metallization on planar-Au substrate, without TMV self-assembly, followed by the $300{ }^{\circ} \mathrm{C}$ annealing process). The differences in charge storage performance between the three electrodes were analyzed in correlation with changes in both the double layer portion of the charge capacity and electrode morphologies (examined using JEM 2100 FEG-TEM and Tescan XEIA FEG-SEM) - in correlation with the changes in electrochemical impedance spectroscopy (EIS) - through charge/discharge cycling to investigate the cause of nonlinear charge capacity increase phenomena observed during the initial charge/discharge cycles.

\section{Results and discussion}

\subsection{XPS analysis of $\mathrm{NiO}$ formation on $\mathrm{TMV} / \mathrm{Ni}$}

TMV/Ni electrodes annealed at the four different temperatures (room temperature, $200{ }^{\circ} \mathrm{C}, 300{ }^{\circ} \mathrm{C}$, and $400{ }^{\circ} \mathrm{C}$ ) are analyzed using XPS. The surface sensitive analysis allows clear observation of the increase in $\mathrm{NiO}$ content on TMV/Ni surfaces with the increase in annealing temperatures. Fig. 3 compares the XPS spectrum of $\mathrm{Ni} 2 \mathrm{p}_{3 / 2}$ and $\mathrm{O} 1 \mathrm{~s}$ from the four samples, and three clear indications of $\mathrm{NiO}$ formation are observed from the spectrum analysis: 1) $\mathrm{NiO}$ formation over the $\mathrm{Ni}$ surface results in the peak 
intensity/area percentage reduction and increase at $852.2 \mathrm{eV}\left(\mathrm{Ni} 2 \mathrm{p}_{3 / 2}\right.$, Fig. 3a-c) and $529.5 \mathrm{eV}(\mathrm{O} 1 \mathrm{~s}$, Fig. 3e-f), respectively, with more abrupt change at $300{ }^{\circ} \mathrm{C}$. 2) The plots in Fig. $3 \mathrm{~d}$ and $3 \mathrm{~h}$ are unique spectrum configurations for crystalline nickel oxide with the peaks revealed at $854.2 \mathrm{eV}$ and $529.5 \mathrm{eV}$ for Ni $2 p_{3 / 2}$ and $\mathrm{O} 1 \mathrm{~s}$, respectively [23]. 3) The complete removal of the peak at $852.2 \mathrm{eV}$ from Ni $2 \mathrm{p}_{3 / 2}$ indicates increased growth of $\mathrm{NiO}$ on/into the $\mathrm{Ni}$ at higher annealing temperatures [24].

\subsection{Core (TMV/Ni)/shell $(\mathrm{NiO})$ nanorod and hierarchical-Ni/NiO electrodes}

The uniform formation of $\mathrm{NiO}$ on a TMV/Ni nanorod after the $300{ }^{\circ} \mathrm{C}$ annealing process is verified in STEM in Fig. 4a. The obtained high-angle annular dark-field (HAADF) image clearly shows the TMV/Ni-core covered by $\mathrm{NiO}$-shell via image contrast variation reflecting the differences in atomic numbers of the constituent materials. Also, the EELS analysis further confirms the core-shell nanorod structures with $\mathrm{Ni}$ and $\mathrm{O}$ scanning profiles along the cross-section of the rod structure. The resulting TMV/Ni/NiO nanorod electrode features $\sim 130 \mathrm{~nm}$ final thickness, majorly defined by duration of electroless $\mathrm{Ni}$ coating process (4 minutes), with uniform coating of a thin $\mathrm{NiO}$ active layer having continuous electrical connection with the underlying $\mathrm{Ni}$ current collector. The thickness of TMV/Ni/NiO nanorod electrode is $\sim 50 \%$ thinner than previously reported TMV templated electrodes (TMV/Ni/TiO ${ }_{2}$, $\mathrm{TMV} / \mathrm{Ni} / \mathrm{Si}$, TMV/Ni $/ \mathrm{V}_{2} \mathrm{O}_{5}$, etc.), which required additional deposition of 30 to $60 \mathrm{~nm}$-thick active layers over TMV/Ni [19-21]. This represents a significant advantage of the annealing process resulting in minimal blockage of the spacings between TMV/Ni rods during the active layer formation allowing full access of electrolytes into the open nanocavities and active layers for optimal performances.

The final electrode structure is shown in the diagonal and cross-sectional SEM images in Fig. 4b and 4c, respectively. The fabricated Au-coated Si micropillars are approximately $70 \mu \mathrm{m}$ tall with $7 \mu \mathrm{m}$ and 14 $\mu \mathrm{m}$ dimensions for pillar diameter and spacing between nearest neighboring pillars, respectively. The hierarchical $\mathrm{Ni} / \mathrm{NiO}$ electrodes are successfully fabricated via formation of an ultra-high density TMV- 
based active network over the high-aspect-ratio micropillar arrays. As clearly shown in Fig. 4c, the IPA treatment of the electrode surface does not hinder structural stability of TMVs during their self-assembly process yet allows complete and uniform coating of the biological scaffolds along the micropillar surfaces into the deep microcavities. Based on our previous reports (up to 7-fold increase in energy densities by TMV nanostructures) [20], and the calculated surface area enhancement factor $(\times 4.5)$ from the micropillar arrays, nearly 30 -fold increase in areal charge capacity $\left(\mu \mathrm{Ah}^{-2}\right)$ is expected in electrochemical performance characterization.

\subsection{Electrochemical performance characterization}

\subsubsection{Charge capacity dependance on annealing temperature}

Based on the XPS analysis results, nanostructured electrodes (TMV/Ni on planar Au substrate) were annealed at temperatures above $200{ }^{\circ} \mathrm{C}\left(250{ }^{\circ} \mathrm{C}, 300{ }^{\circ} \mathrm{C}, 350^{\circ} \mathrm{C}\right.$, and $\left.400{ }^{\circ} \mathrm{C}\right)$. The charge storage performance of the electrodes was evaluated by comparing the galvanostatic discharge capacity measured from the second charge/discharge cycle at $2 \mathrm{~mA} \mathrm{~cm}^{-2}$. As shown in Fig. 5a, the areal capacity of the electrode results in a significant increase at $300{ }^{\circ} \mathrm{C}$ annealing condition $\left(20.5 \mu \mathrm{Ah} \mathrm{cm}^{-2}\right)$ compared to 250 ${ }^{\circ} \mathrm{C}$ annealing condition $\left(4.3 \mu \mathrm{Ah} \mathrm{cm}^{-2}\right)$, while the electrodes annealed at higher temperatures show degraded performance with $10.2 \mathrm{uAh} \mathrm{cm}^{-2}$ and $2.2 \mathrm{uAh} \mathrm{cm}^{-2}$ for $350{ }^{\circ} \mathrm{C}$ and $400{ }^{\circ} \mathrm{C}$ annealing conditions, respectively. The significant increase at the $300{ }^{\circ} \mathrm{C}$ annealing condition can be explained by the facile thermal oxidation process of $\mathrm{Ni}$ at $300{ }^{\circ} \mathrm{C}$ [25]. The lower capacities measured from samples processed at temperatures above $300{ }^{\circ} \mathrm{C}$ can be attributed to both an increase in active layer thickness which limits rate capability, and the growth of oxides on/into Ni layer resulting in loss of conductivity of the electrode system. The cyclic voltammetry (CV) curves for electrodes annealed at $300{ }^{\circ} \mathrm{C}$, shown in Fig. 5b, exhibit reversible faradaic reaction with clear corresponding redox peaks for $\mathrm{NiO}$ confirming its battery-type charge storage behavior within a wide range of scan rates $\left(10-100 \mathrm{mV} \mathrm{s}^{-1}\right)$. 


\subsubsection{Charge storage performance of hierarchical-Ni/NiO}

The $\mathrm{NiO}$ electrodes are prepared in three different electrode geometries (planar-, nanostructured-, and hierarchical-Ni/NiO) to evaluate the increase in areal charge capacity of the hierarchical-Ni/NiO. All electrodes are annealed at $300{ }^{\circ} \mathrm{C}$ for two hours. The areal discharge capacity measured by galvanostatic charge/discharge $\left(2 \mathrm{~mA} \mathrm{~cm}^{-2}\right)$ is compared between the three electrode types over the first 500 cycles. As shown in Fig. 6a, the electrodes are successfully cycled with no signs of operational failure with the charge capacities ordered in expected hierarchy (planar $<$ nanostructured $<$ hierarchical). However, a significant nonlinear capacity increase is observed over the 500 cycles for the nanostructured- and hierarchical-Ni/NiO (26\% and $193 \%$, respectively), while the planar-Ni/NiO show minimal increase of $7 \%$. Comparing the nanostructured- and planar-Ni/NiO, an approximately 10 -fold increase in areal capacity is achieved at the $500^{\text {th }}$ cycle $\left(24.3 \mu \mathrm{Ah} \mathrm{cm}{ }^{-2}\right.$ vs. $\left.2.5 \mu \mathrm{Ah} \mathrm{cm} \mathrm{cm}^{-2}\right)$, which is a noticeable improvement from our previous report (7-fold increase) [20]. The increased enhancement factor from 7 to 10 is assigned to the preserved TMV/Ni morphology during the active layer formation step as discussed in previous section. For the hierarchical electrode, the initial capacity is measured lower than expected. However, the capacity reaches a very high value of $81.4 \mu \mathrm{Ah} \mathrm{cm}^{-2}$ after the nonlinear increase by the end of the $500^{\text {th }}$ cycle. This exceeds that of the nanostructured- $\left(24.3 \mu \mathrm{Ah} \mathrm{cm}^{-2}\right)$ and planar-Ni/NiO $(2.5 \mu \mathrm{Ah}$ $\mathrm{cm}^{-2}$ ) by 3.3 and 32.6 times, respectively. It is hypothesized that the capacity increase is due to the increase in both active material (oxidized $\mathrm{Ni}$ ) and surface area/mesoporosity during the charge/discharge cycling which will be discussed further in the following sections.

\subsubsection{Analysis of charge capacity increase phenomena and discussions}

To test our hypothesis, the change in active surface area for the different electrode structures was examined during the initial capacity increase. From the discharge plots in Fig. 6b-d (displaying $2^{\text {nd }}, 250^{\text {th }}$, and $500^{\text {th }}$ discharge cycles per electrode types), the amount of double layer charge, which has dominant 
dependence on the active surface area, is estimated from the potential range outside the major redox potential window [26]. Specifically, the double layer charge is calculated in the potential range of 0.35 $0.5 \mathrm{~V}$ for the three sample types, and the values are compared with the total charge $(0-0.5 \mathrm{~V})$ at three different cycles $\left(2^{\text {nd }}, 250^{\text {th }}\right.$, and $\left.500^{\text {th }}\right)$. A similar increasing trend between the double layer and total charge can be observed (Fig. 6b-d) from all three electrode types, which strongly supports the assumption of the active area increase during the initial cycling. We believe that the larger increase in areal capacity observed for the hierarchical versus the nanostructured electrodes is attributed to the dual length-scale architecture of the hierarchical electrode, particularly the micropillar morphology. We have also examined the rate dependence of the capacity increase of the hierarchical electrodes. As shown in Fig. 6e, lower current densities show higher rate in the initial capacity increase per cycles due to the increased time of charge diffusion at the electrode/electrolyte boundary. This result holds for all three electrodes as saturation in the areal capacity increase is reached faster at lower current densities. The hierarchical electrode tested at $2 \mathrm{~mA} \mathrm{~cm}^{-2}$ show excellent cycle stability up to 1500 charge/discharge cycles without any capacity fading (Fig. 6e).

To further understand the capacity increase phenomena, changes in both the NiO layer thickness and the nanostructure morphology during the initial cycles were examined in electron microscopy images as shown in Fig. 7. The TEM images shown in Fig. 7a through 7c compare the electrode surfaces after different steps in the experimental process (Fig. 7a: pristine electroless Ni, Fig. $7 \mathrm{~b}$ : after $300{ }^{\circ} \mathrm{C}$ annealing step, Fig. 7c: after 20 charge/discharge cycles at $2 \mathrm{~mA} \mathrm{~cm}^{-2}$ ). The thickness of the $\mathrm{NiO}$ layer was approximately determined by analyzing the apparent difference in TEM image contrast between metal (Ni) and dielectric $(\mathrm{NiO})$ layers. Comparing the thickness of the red shadowed region between the dotted line boundaries, a significant increase in $\mathrm{NiO}$ thickness can be observed from pristine $\mathrm{Ni}$ (residual oxide) to the electrochemically cycled electrodes. This implies that there is an increase in active $\mathrm{NiO}$ content not 
only during the annealing process but also during the initial electrochemical cycling in $\mathrm{KOH}$ electrolyte. Specifically the $\mathrm{Ni}$ underneath the thermal $\mathrm{NiO}$ layer is being electrochemically oxidized during charging and participates in charge storage reactions in the subsequent cycles [26, 27]. The SEM images shown in Fig. $7 \mathrm{~d}$ and $7 \mathrm{e}$ compares the nanostructure morphology of the TMV/Ni/NiO electrodes (Fig. $7 \mathrm{~d}$ ) before and (Fig. 7e) after a 1000 charge/discharge cycles. A significant change in surface morphology along with an increase in diameter of the nanorod electrodes are observed after the extended number of electrochemical cycling. The observations combined suggest two different mechanisms involved in the material activation process during the initial cycling; 1) uniform growth of the NiO layer underneath the annealed oxide layer (Fig. 7c), and 2) formation of a complex mesoscale structure within the $\mathrm{NiO}$ film (Fig. 7e). Considering these observations in correlation with the non-linear capacity increase phenomena, it can be inferred that the suggested activation stages interplay significant role increasing the charge capacity along the initial cycle, and the non-linear increase, reaching saturation level, is possibly due to the concurrent loss in nanostructure porosity by the expansion in diameter of nanorods.

The EIS analysis $(0.25 \mathrm{~V}$ working electrode potential vs. $\mathrm{Ag} / \mathrm{AgCl}$ with $20 \mathrm{mV}$ AC perturbation sweep from $1 \mathrm{~Hz}$ to $100 \mathrm{kHz}$ ) shown in Fig. 8 also supports the idea of complex activation of $\mathrm{NiO}$ during the initial cycling. The analysis was conducted at every 100 charge/discharge cycle intervals over the initial 500 cycles. The Nyquist plots can be analyzed by looking at the two frequency regions where the plot generally displays semi-circular plot configuration at high frequencies reflecting combination of the bulk electrolyte resistance $\left(R_{s}\right)$, charge transfer resistance $\left(R_{c t}\right)$, and double layer capacitance $\left(C_{d l}\right)$, while the straight line in the lower frequency region represents diffusion-governed electrochemical processes, interpreted by Warburg-impedance $\left(\mathrm{Z}_{\mathrm{w}}\right)$. The Nyquist plot acquired from planar- and nanostructured$\mathrm{Ni} / \mathrm{NiO}$ electrodes are shown in Fig. $8 \mathrm{a}$ and Fig. $8 \mathrm{~b}$, respectively. The charge transfer resistance of the planar-Ni/NiO is estimated to be $\sim 35 \Omega$ from the arc-shape in the high frequency region $(>137 \mathrm{~Hz}$ ) using 
Randles-equivalent circuit (Fig. 8c). Over the initial 500 cycles, there is no noticeable change in the plot configuration which is in good correspondence with the steady charge storage performance of the planar$\mathrm{Ni} / \mathrm{NiO}$ electrode (Fig. 8d). However, the plot acquired from the nanostructured-Ni/NiO (Fig. 8d) shows a significant change over the initial cycles. The overall impedance of the electrode is largely reduced compared to the planar- $\mathrm{Ni} / \mathrm{NiO}$ attributed to the increase in active surface area by the TMV scaffolds. Also, the semi-circular plot configuration at the high frequency region $(>867 \mathrm{~Hz})$, is significantly depressed/diminished showing almost a linear line in all consecutive measurements. This is an indication of low $\mathrm{R}_{\mathrm{ct}}$ of the nanostructured-Ni/NiO better facilitating faradaic charge storage reactions [29,30]. More interestingly, the appearance of the arc-shape in the low-frequency linear lines $(<137 \mathrm{~Hz})$ become distinctive along with the increase in cycle numbers - implying both the emergence of a secondary charge transfer kinetics and reduction of the involved $\mathrm{R}_{\mathrm{ct}}$ along with the activation phases of the NiO layer during the initial cycling.

These results combined strongly imply that the electrochemical formation of $\mathrm{NiO}\left(\right.$ or $\left.\mathrm{Ni}(\mathrm{OH})_{2}\right)$ content and an increase of the mesoscale active network ultimately cause the increase in active surface area resulting in enhanced charge storage performance. Also, the non-linear increase and saturation of the charge capacity increase suggest that this electrochemically induced process is self-limited most likely due to limited charge diffusion and reduced electrical conductivity as a result of the active layer growth into the TMV/Ni-core. We believe that the above experiments combined can provide further understanding of previous reports showing similar capacity increase phenomena in micro/nanostructured $\mathrm{NiO}$ electrodes for different ECS applications $[5,11,12,15]$.

\section{Conclusion}

The hierarchical-Ni/NiO electrodes were fabricated based on the TMV/Ni robust nanostructure platform integrated with $\mathrm{Si}$ micropillar arrays. The uniform formation of thin $\mathrm{NiO}$ active layer is achieved by a 
simple thermal oxidation, and the formation of TMV/Ni (core)/NiO (shell) nanorod is confirmed by STEM and EELS analysis. Both the well-preserved nanostructural porosity of TMV/Ni after the annealing process and the successful integration of TMVs with Si microstructures allowed unprecedented charge capacity increase factors $-\times 10$ with the nanostructured electrodes, and $\times 32.6$ with the hierarchical electrodes compared to the planar ones - when compared with other TMV-templated ECS systems reported previously. Also, the analysis and discussions on the interesting charge capacity increase phenomena of the TMV/Ni/NiO electrodes should be applicable for understanding the electrochemical behavior and degradation mechanisms of other micro/nanostructured $\mathrm{NiO}$ electrodes investigated for ECS applications. This work greatly expands the potential applications of TMVs for next generation ECS devices with simple fabrication and excellent electrochemical cycle stability. Under a condition which the uniform formation of other transition metal layers can be achieved over TMVs, we believe that the annealing process can be further expanded for creating nano-core (metal)/shell (metal oxide) electrodes to benefit additional advanced ECS systems.

\section{Acknowledgements}

This work was funded by Nanostructures for Electrical Energy Storage, an Energy Frontiers Research Center funded by the U.S. Department of Energy, Office of Science, Office of Basic Energy Sciences [Award Number DESC0001160]. The authors would like to thank Professor James N. Culver for providing access to their lab for TMV purification, Dr. Karen Gaskell for helping us to acquire XPS data. Also, we acknowledge the support of the Maryland NanoCenter.

\section{References}

[1] H. Chen, T.N. Cong, W. Yang, C. Tan, Y. Li, Y. Ding, Progress in electrical energy storage system: A critical review, Prog. Nat. Sci. 19 (2009) 291-312. doi:10.1016/j.pnsc.2008.07.014.

[2] A.S. Aricò, P. Bruce, B. Scrosati, J.-M. Tarascon, W. van Schalkwijk, Nanostructured materials for 
advanced energy conversion and storage devices., Nat. Mater. 4 (2005) 366-77. doi:10.1038/nmat1368.

[3] S.M. Chen, R. Ramachandran, V. Mani, R. Saraswathi, Recent advancements in electrode materials for the high-performance electrochemical supercapacitors: A review, Int. J. Electrochem. Sci. 9 (2014) 4072-4085.

[4] G. Wang, L. Zhang, J. Zhang, A review of electrode materials for electrochemical supercapacitors, Chem. Soc. Rev. 41 (2012) 797. doi:10.1039/c1cs15060j.

[5] A. Caballero, L. Hernán, J. Morales, Z. González, A.J. Sánchez-Herencia, B. Ferrari, A highcapacity anode for lithium batteries consisting of mesoporous $\mathrm{NiO}$ nanoplatelets, Energy and Fuels. 27 (2013) 5545-5551. doi:10.1021/ef400797r.

[6] F. Luan, G. Wang, Y. Ling, X. Lu, H. Wang, Y. Tong, X.-X. Liu, Y. Li, High energy density asymmetric supercapacitors with a nickel oxide nanoflake cathode and a 3D reduced graphene oxide anode., Nanoscale. 5 (2013) 7984-90. doi:10.1039/c3nr02710d.

[7] G.H. Yue, Y.C. Zhao, C.G. Wang, X.X. Zhang, X.Q. Zhang, Q.S. Xie, Flower-like nickel oxide nanocomposites anode materials for excellent performance lithium-ion batteries, Electrochim. Acta. 152 (2015) 315-322. doi:10.1016/j.electacta.2014.11.177.

[8] Z. Fan, J. Liang, W. Yu, S. Ding, S. Cheng, G. Yang, Y. Wang, Y. Xi, K. Xi, R.V. Kumar, Ultrathin $\mathrm{NiO}$ nanosheets anchored on a highly ordered nanostructured carbon as an enhanced anode material for lithium ion batteries, Nano Energy. $16 \quad$ (2015) 152-162. doi:10.1016/j.nanoen.2015.06.009.

[9] T. Brousse, D. Belanger, J.W. Long, To Be or Not To Be Pseudocapacitive?, J. Electrochem. Soc. 162 (2015) A5185-A5189. doi:10.1149/2.0201505jes.

[10] Y. Zou, Y. Wang, NiO nanosheets grown on graphene nanosheets as superior anode materials for 
Li-ion batteries., Nanoscale. 3 (2011) 2615-2620. doi:10.1039/c1nr10070j.

[11] M. Hasan, M. Jamal, K.M. Razeeb, Coaxial NiO/Ni nanowire arrays for high performance pseudocapacitor applications, Electrochim. Acta. $60 \quad$ (2012) 193-200. doi:10.1016/j.electacta.2011.11.039.

[12] J.-H. Kim, S.H. Kang, K. Zhu, J.Y. Kim, N.R. Neale, A.J. Frank, Ni-NiO core-shell inverse opal electrodes for supercapacitors., Chem. Commun. (Camb). 47 (2011) 5214-5216. doi:10.1039/c0cc05191h.

[13] L. Yang, L. Qian, X. Tian, J. Li, J. Dai, Y. Guo, D. Xiao, Hierarchically porous nickel oxide nanosheets grown on nickel foam prepared by one-step in situ anodization for high-performance supercapacitors, Chem. - An Asian J. 9 (2014) 1579-1585. doi:10.1002/asia.201402175.

[14] H. Wang, H. Yi, X. Chen, X. Wang, Facile synthesis of a nano-structured nickel oxide electrode with outstanding pseudocapacitive properties, Electrochim. Acta. 105 (2013) 353-361. doi:10.1016/j.electacta.2013.05.031.

[15] X. Dai, D. Chen, H. Fan, Y. Zhong, L. Chang, H. Shao, J. Wang, J. Zhang, C.N. Cao, $\mathrm{Ni}(\mathrm{OH}) 2 / \mathrm{NiO} / \mathrm{Ni}$ composite nanotube arrays for high-performance supercapacitors, Electrochim. Acta. 154 (2015) 128-135. doi:10.1016/j.electacta.2014.12.066.

[16] L. Yu, G. Zhang, C. Yuan, X.W.D. Lou, Hierarchical NiCo2O4@MnO2 core-shell heterostructured nanowire arrays on Ni foam as high-performance supercapacitor electrodes, Chem. Commun. 49 (2013) 137-139. doi:10.1039/c2cc37117k.

[17] E. Royston, A. Ghosh, P. Kofinas, M.T. Harris, J.N. Culver, Self-assembly of virus-structured high surface area nanomaterials and their application as battery electrodes, Langmuir. 24 (2008) 906912. doi:10.1021/la7016424.

[18] M. Gnerlich, H. Ben-Yoav, J.N. Culver, D.R. Ketchum, R. Ghodssi, Selective deposition of 
nanostructured ruthenium oxide using Tobacco mosaic virus for micro-supercapacitors in solid Nafion electrolyte, J. Power Sources. 293 (2015) 649-656. doi:10.1016/j.jpowsour.2015.05.053.

[19] X. Chen, K. Gerasopoulos, J. Guo, A. Brown, C. Wang, R. Ghodssi, J.N. Culver, Virus-enabled silicon anode for lithium-ion batteries, ACS Nano. 4 (2010) 5366-5372. doi:10.1021/nn100963j.

[20] K. Gerasopoulos, E. Pomerantseva, M. McCarthy, A. Brown, C. Wang, J. Culver, R. Ghodssi, Hierarchical three-dimensional microbattery electrodes combining bottom-up self-assembly and top-down micromachining, ACS Nano. 6 (2012) 6422-6432. doi:10.1021/nn301981p.

[21] K. Gerasopoulos, X.L. Chen, J. Culver, C.S. Wang, R. Ghodssi, Self-assembled Ni/TiO2 nanocomposite anodes synthesized via electroless plating and atomic layer deposition on biological scaffolds, Chem. Commun. 46 (2010) 7349-7351. doi:Doi 10.1039/C0cc01689f.

[22] K. Gerasopoulos, M. McCarthy, P. Banerjee, X. Fan, J.N. Culver, R. Ghodssi, Biofabrication methods for the patterned assembly and synthesis of viral nanotemplates., Nanotechnology. 21 (2010) 55304. doi:10.1088/0957-4484/21/5/055304.

[23] A.N. Mansour, Characterization of NiO by XPS, Surf. Sci. Spectra. 3 (1994) 231. doi:10.1116/1.1247751.

[24] S.V. Kumari, M. Natarajan, V.K. Vaidyan, P. Koshy, Surface oxidation of nickel thin films, J. Mater. Sci. Lett. 11 (1992) 761-762. doi:10.1007/BF00729484.

[25] L. De Los Santos Valladares, A. Ionescu, S. Holmes, C.H.W. Barnes, A. Bustamante Domínguez, O. Avalos Quispe, J.C. González, S. Milana, M. Barbone, A.C. Ferrari, H. Ramos, Y. Majima, Characterization of Ni thin films following thermal oxidation in air, J. Vac. Sci. Technol. B, Nanotechnol. Microelectron. Mater. Process. Meas. Phenom. 32 (2014) 51808. doi:10.1116/1.4895846.

[26] Z. Lu, Z. Chang, J. Liu, X. Sun, Stable ultrahigh specific capacitance of NiO nanorod arrays, Nano 
Res. 4 (2011) 658-665. doi:10.1007/s12274-011-0121-1.

[27] D. Zhao, S. Bao, W. Zhou, H. Li, Preparation of hexagonal nanoporous nickel hydroxide film and its application for electrochemical capacitor, 9 (2007) 869-874. doi:10.1016/j.elecom.2006.11.030.

[28] P.A. Nelson, J.M. Elliott, G.S. Attard, J.R. Owen, Mesoporous Nickel / Nickel Oxide s a Nanoarchitectured Electrode, (2002) 524-529.

[29] C. Wu, S. Deng, H. Wang, Y. Sun, J. Liu, H. Yan, Preparation of novel three-dimensional NiO/ultrathin derived graphene hybrid for supercapacitor applications, ACS Appl. Mater. Interfaces. 6 (2014) 1106-1112. doi:10.1021/am404691w.

[30] J.W. Lee, T. Ahn, J.H. Kim, J.M. Ko, J.D. Kim, Nanosheets based mesoporous NiO microspherical structures via facile and template-free method for high performance supercapacitors, Electrochim. Acta. 56 (2011) 4849-4857. doi:10.1016/j.electacta.2011.02.116. 

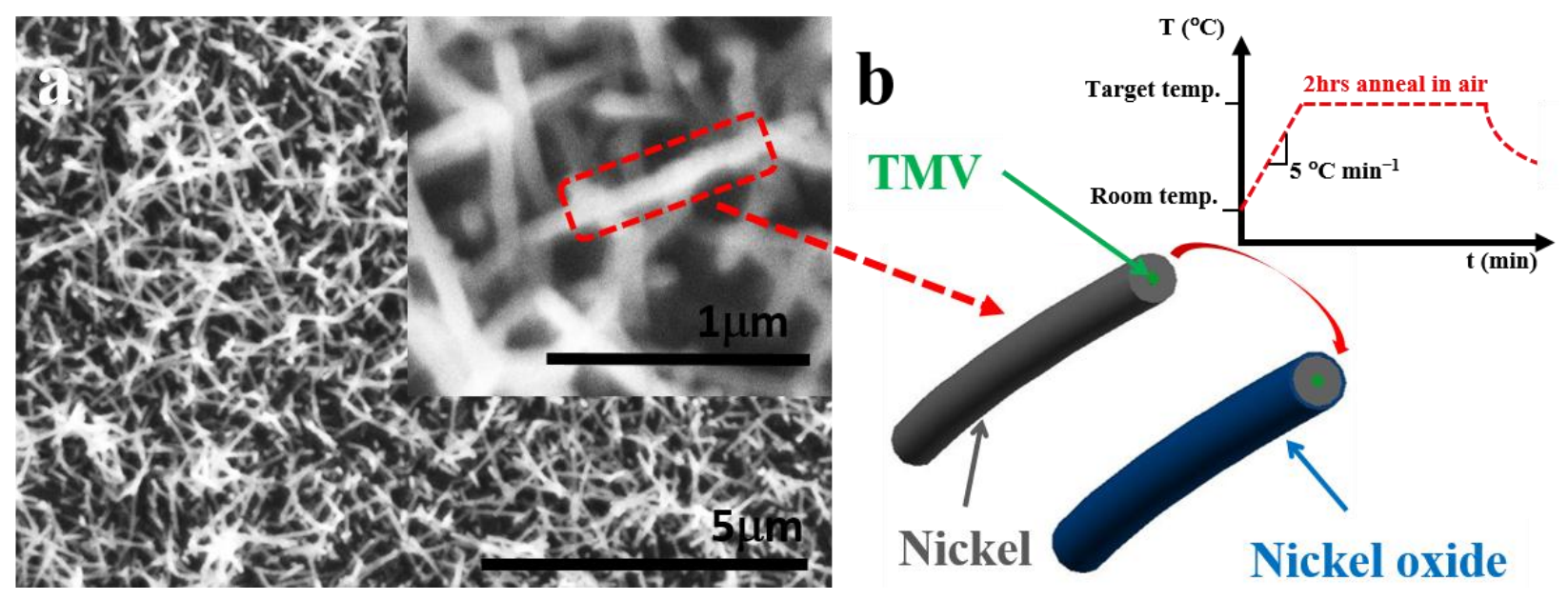

Fig. 1 (a) Top-down SEM image of TMV/Ni nanostructure and (b) schematic description of thermal oxidation process for creating $\mathrm{NiO}$-shell layer over TMV/Ni-core.

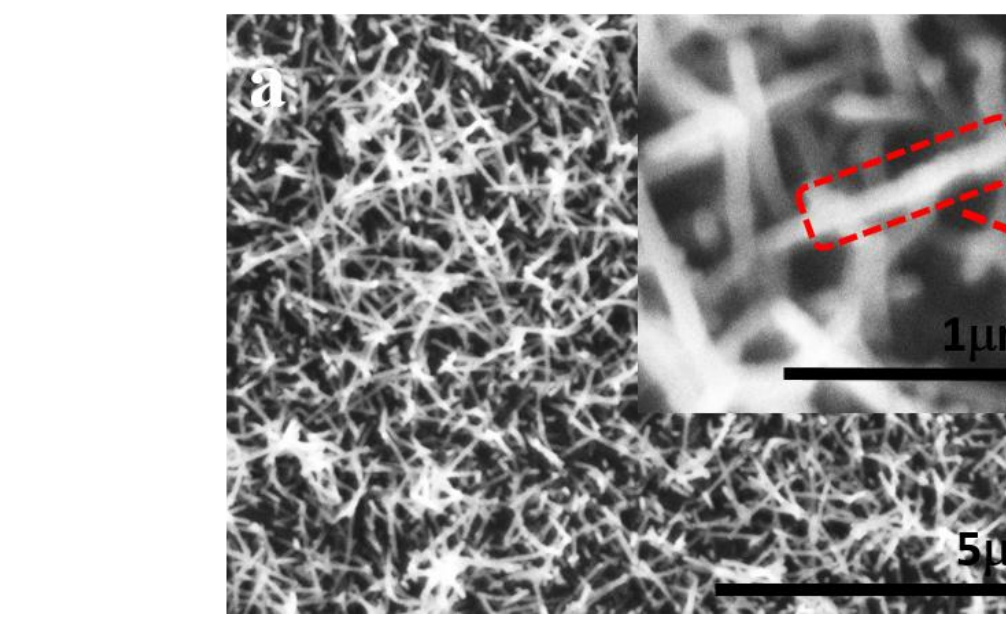
process for creating NiO-shell layer over TMV/Ni-core.

\begin{abstract}
b) schematic description of thermal oxidation
\end{abstract}
tion 
a

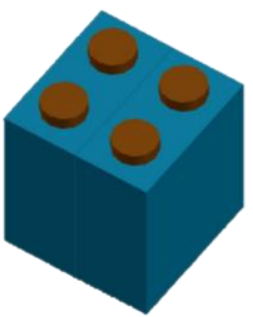

(i) Pattern etch mask

(ii) Etch Si micropillars

b

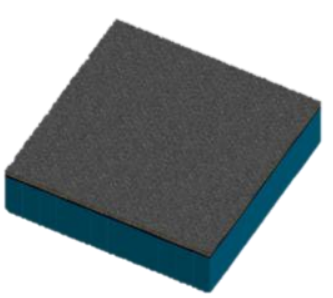

Nanostructured-Ni/NiO
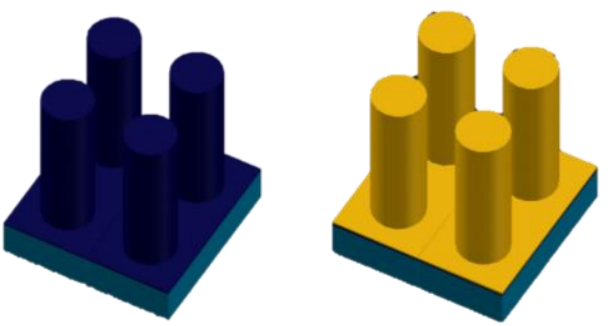

(iii) Surface passivation (iv) $\mathrm{Ti} / \mathrm{Au}$ deposition

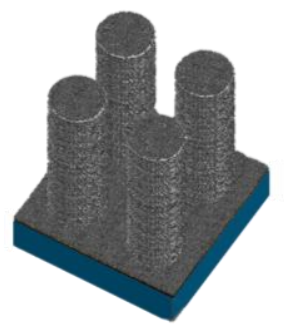

(v) TMV self-assembly and metallization

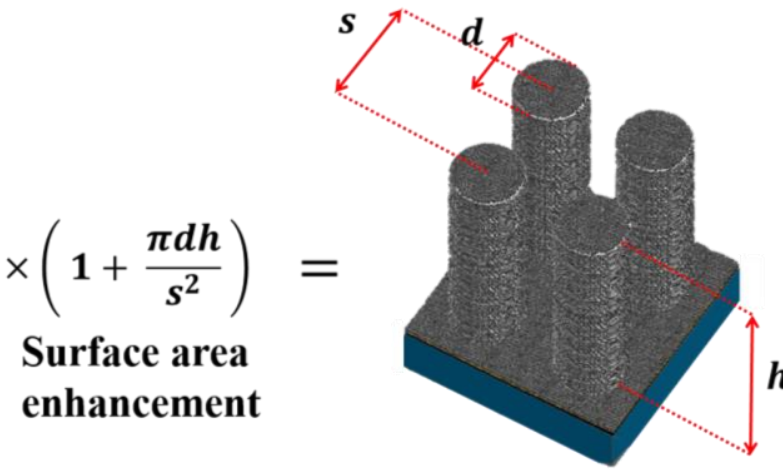

Hierarchical-Ni/NiO
Si substrate

Photoresist (AZ-5214)

- $\mathrm{Si}_{3} \mathrm{~N}_{4}$

Au

Ni-coated TMV

Fig. 2 (a) Fabrication process for hierarchical Ni/NiO electrodes, and (b) description of surface area enhancement factor due to the Si micropillar array structure. 

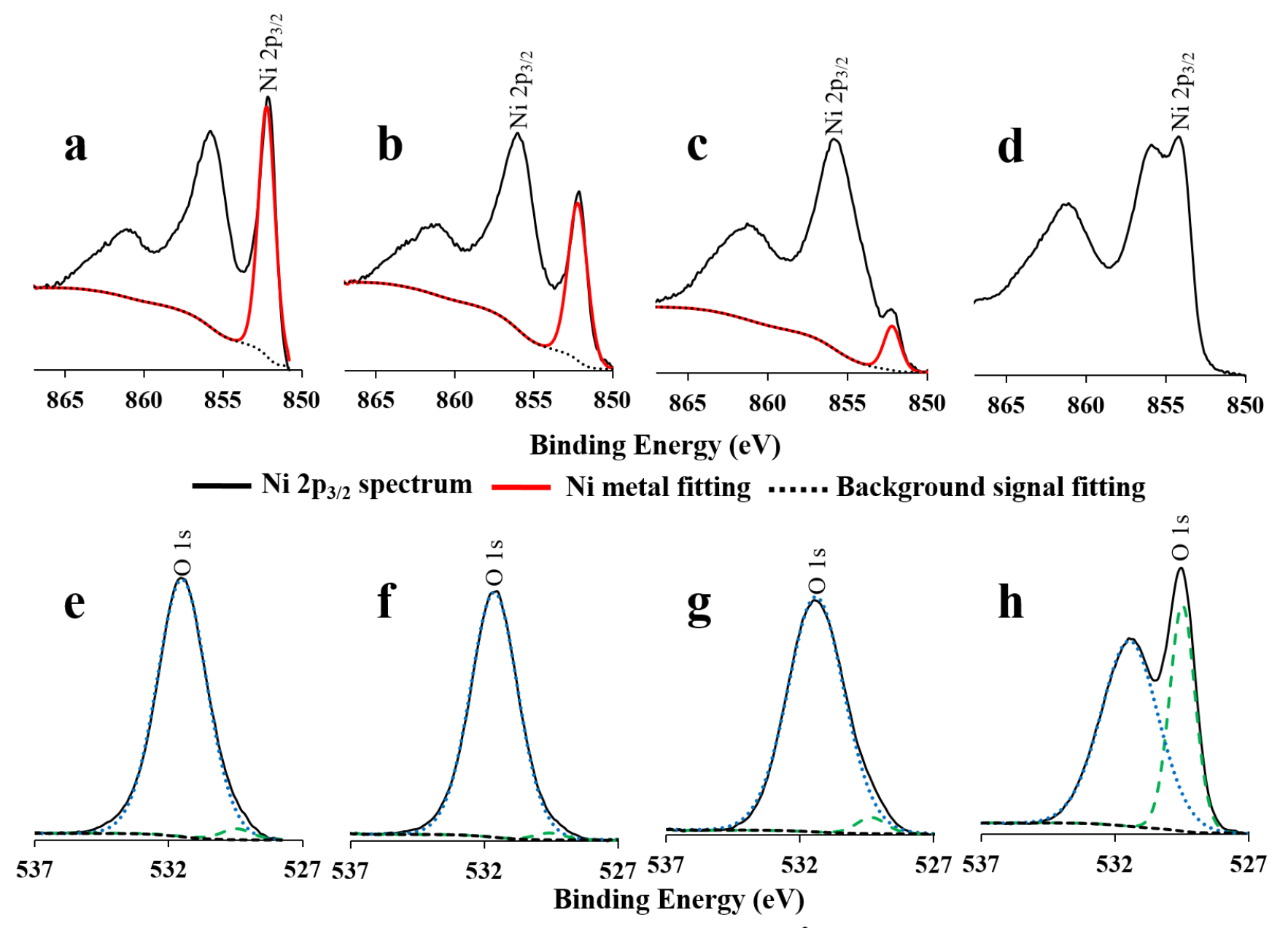

Fig. 3 XPS analysis of (a-d) $\mathrm{Ni} 2 \mathrm{p}_{3 / 2}$ and (e-h) $\mathrm{O} 1 \mathrm{~s}$ from the TMV/Ni electrodes annealed at different temperatures; (a, e) room temperature, (b, f) $200{ }^{\circ} \mathrm{C}$, (c, g) $300{ }^{\circ} \mathrm{C}$, and $(\mathrm{d}, \mathrm{h}) 400{ }^{\circ} \mathrm{C}$. 


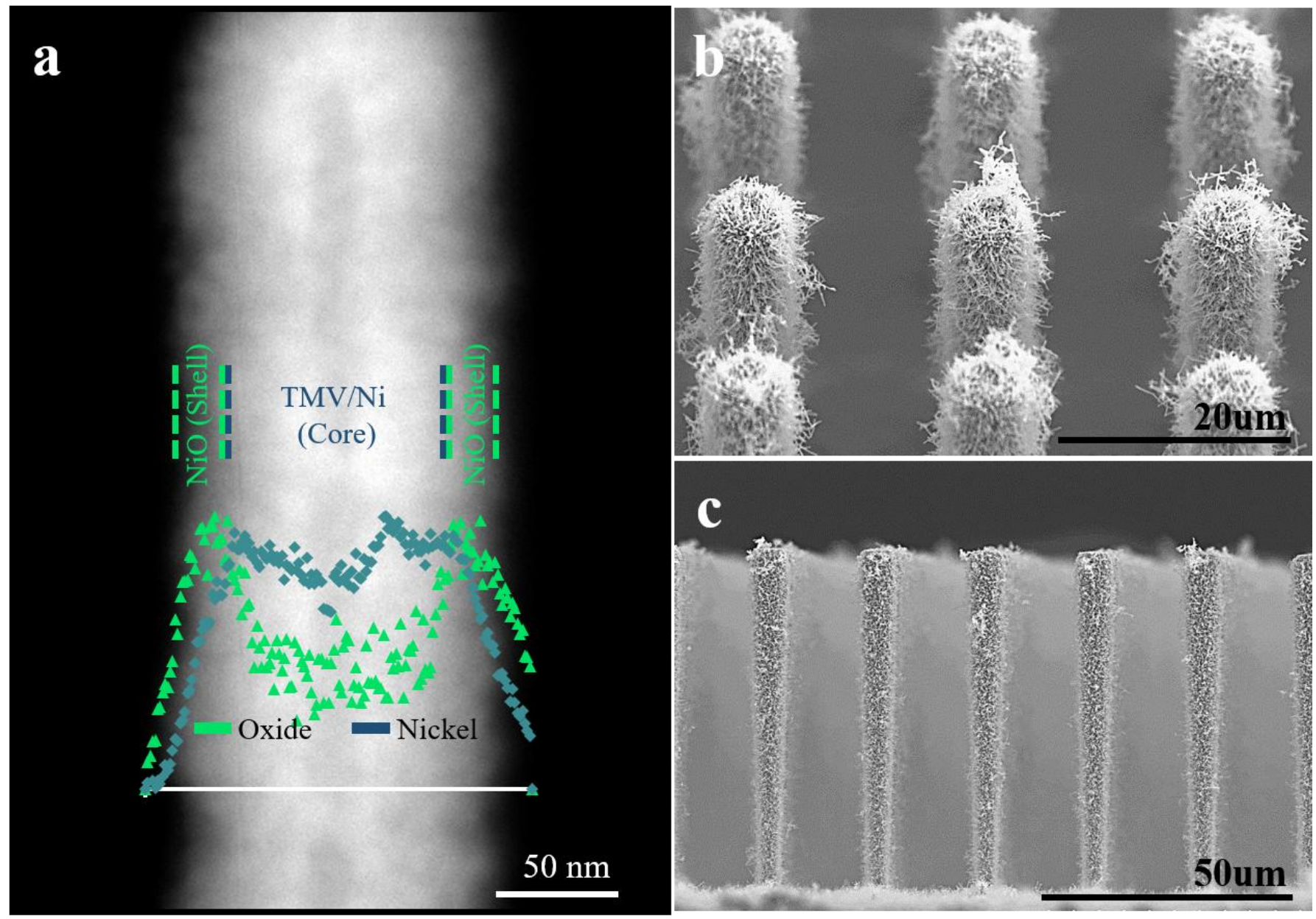

Fig. 4 STEM-EELS analysis and SEM images of the fabricated electrodes: (a) STEM image of a TMV/Ni/NiO nanorod with EELS analysis. (b) Diagonal and (c) cross-sectional view of the hierarchical-Ni/NiO electrodes. 

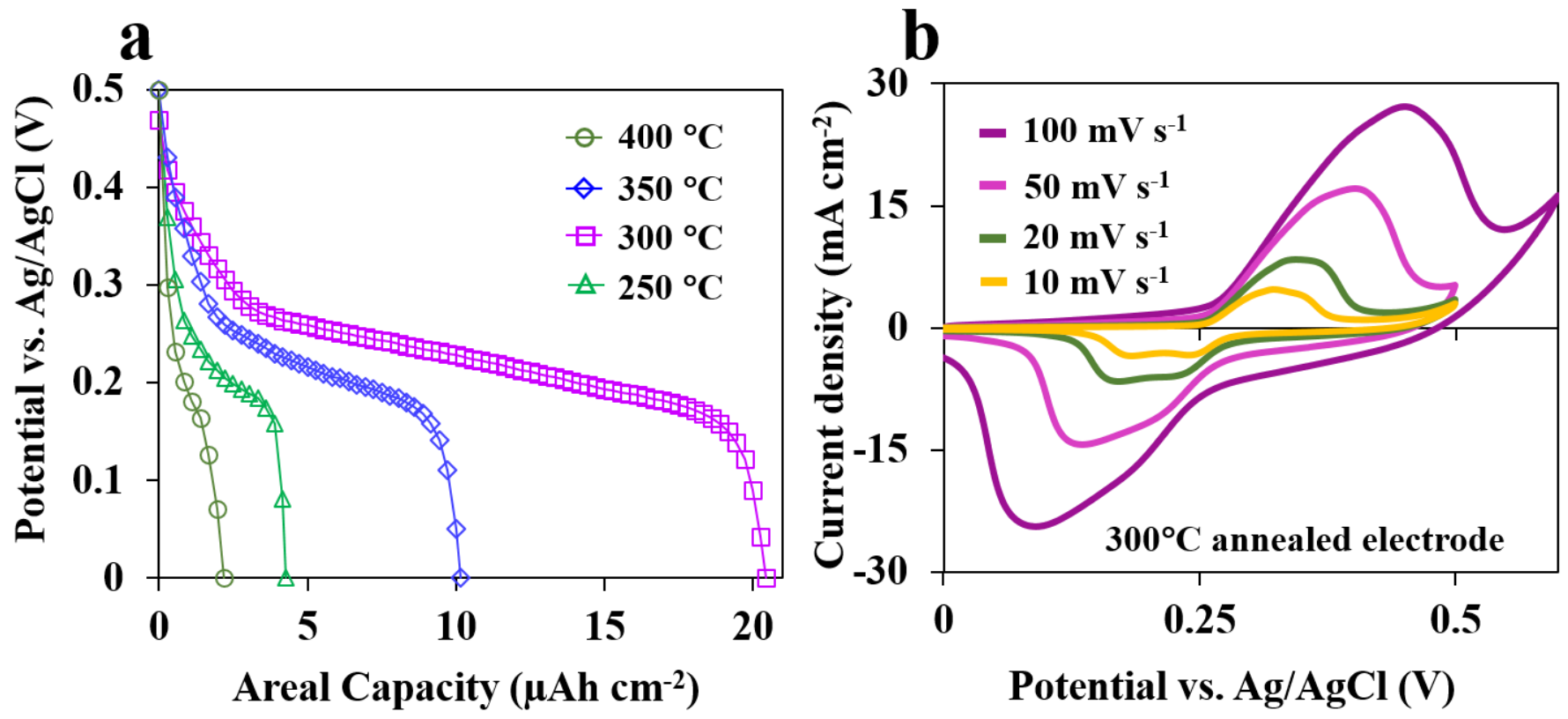

Fig. 5 Electrochemical characterization of nanostructured-Ni/NiO electrodes; (a) Galvanostatic discharge plots of the electrodes annealed at different temperatures. (b) $\mathrm{CV}$ curves of $300{ }^{\circ} \mathrm{C}$-annealed nanostructured-Ni/NiO. 
a

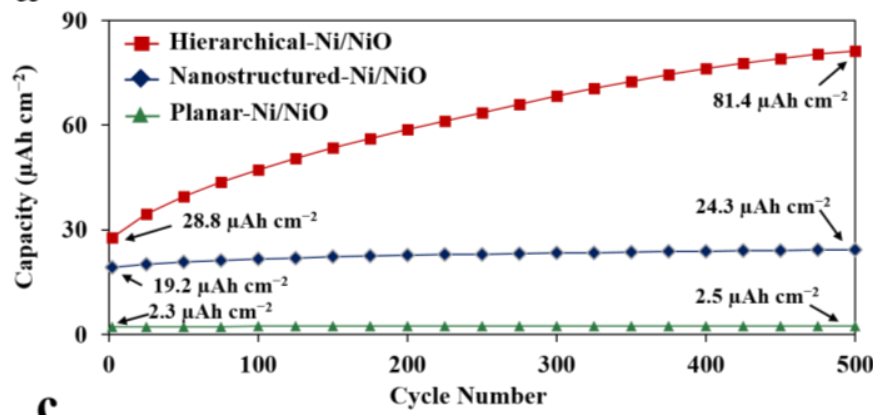

c
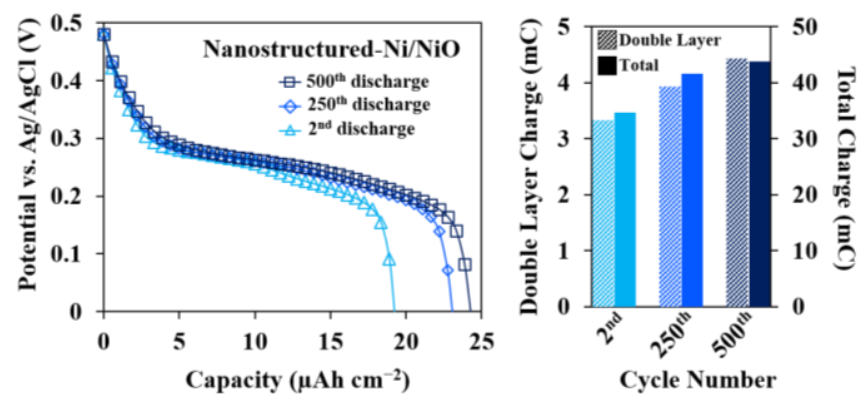

b
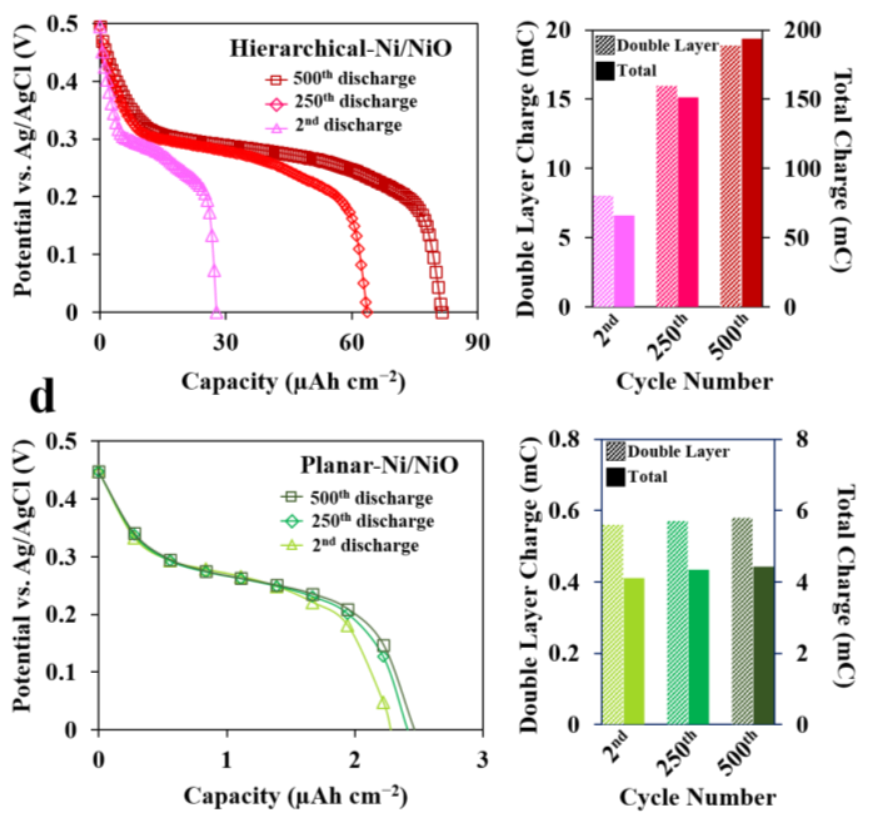

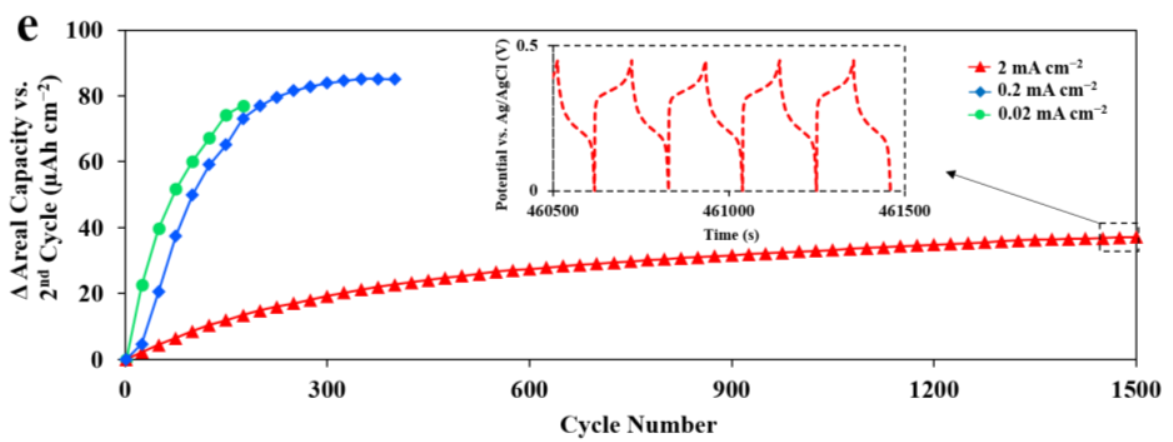

Fig. 6 Comparisons of initial capacity increase for the three different electrode geometries; hierarchical, nanostructured, and planar. (a) Areal capacity of the three electrodes (hierarchical-, nanostructured-, and planar$\mathrm{Ni} / \mathrm{NiO}$ ) over the first 500 galvanostatic cycles at $2 \mathrm{~mA} \mathrm{~cm}^{-2}$. Discharge plots from $2^{\text {nd }}, 250^{\text {th }}$, and $500^{\text {th }}$ cycles with comparisons of estimated double layer and total charges in (b) hierarchical, (c) nanostructured, and (d) planar electrodes. (e) Areal capacity increase of the hierarchical-Ni/NiO at three different current densities $(0.02,0.2$, and $2 \mathrm{~mA} \mathrm{~cm}^{-2}$ ). 

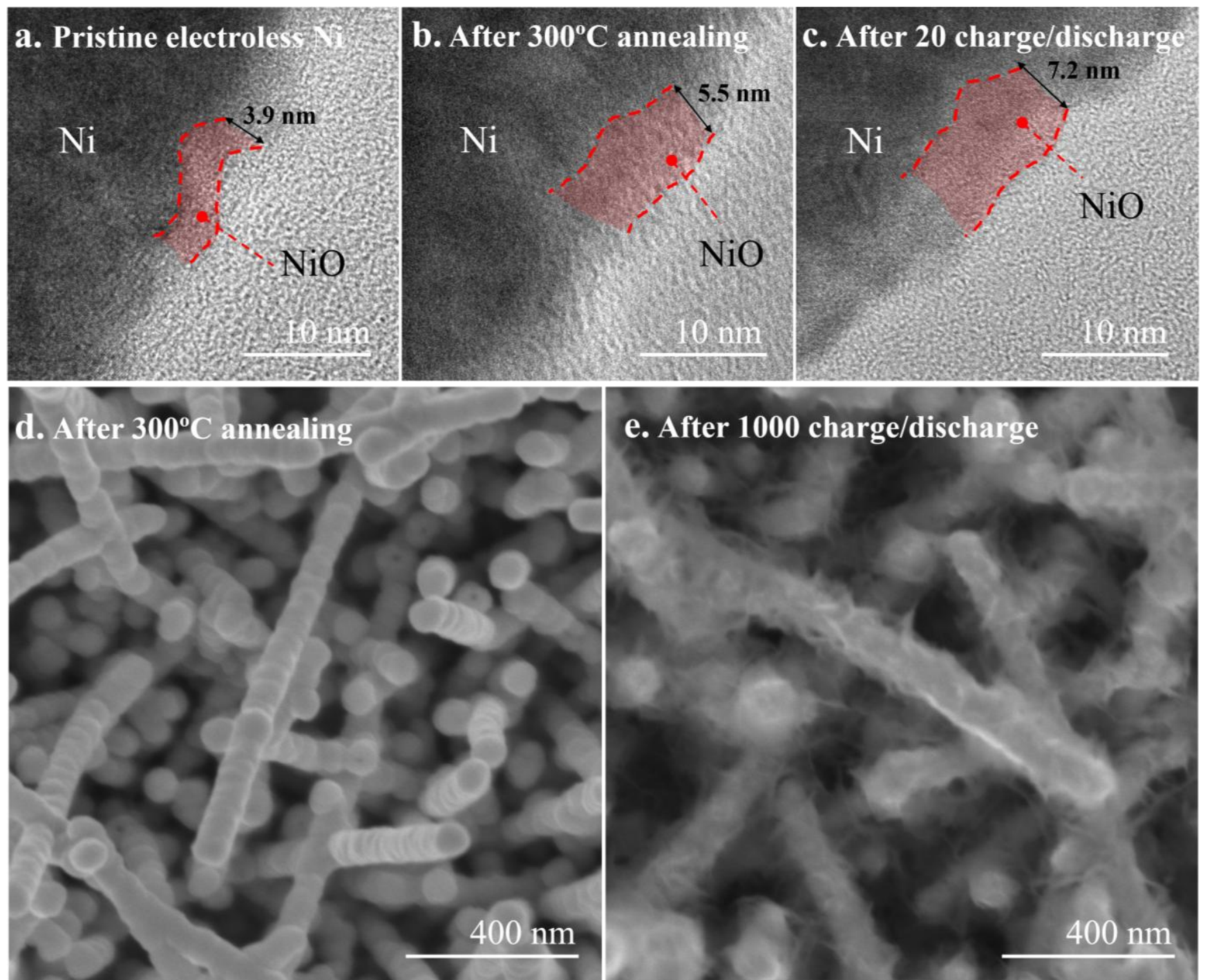

Fig. 7 Electron microscopy images comparing TMV/Ni/NiO surfaces and structures after different steps in the experimental process. (top) TEM images comparing thickness of $\mathrm{NiO}$ layers at three different conditions: (a) pristine electroless $\mathrm{Ni}$ on $\mathrm{TMV}$, (b) after $300{ }^{\circ} \mathrm{C}$ annealing of $\mathrm{TMV} / \mathrm{Ni}$, and (c) after 20 galvanostatic charge/discharge cycles of TMV/Ni/NiO at $2 \mathrm{~mA} \mathrm{~cm}^{-2}$. (bottom) SEM images comparing TMV/Ni/NiO (d) before and (e) after 1000 galvanostatic charge/discharge cycles at $2 \mathrm{~mA} \mathrm{~cm}^{-2}$. 

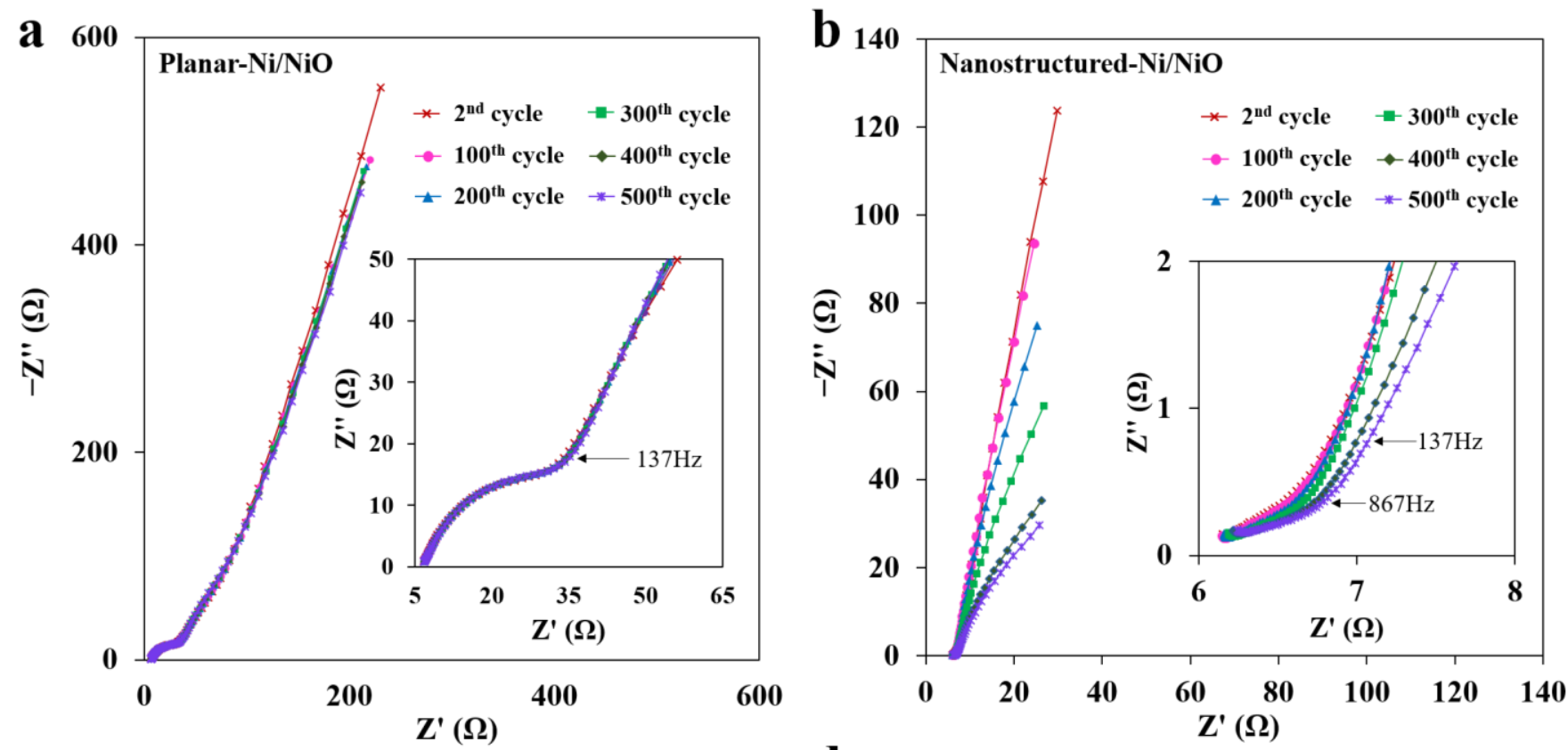

c

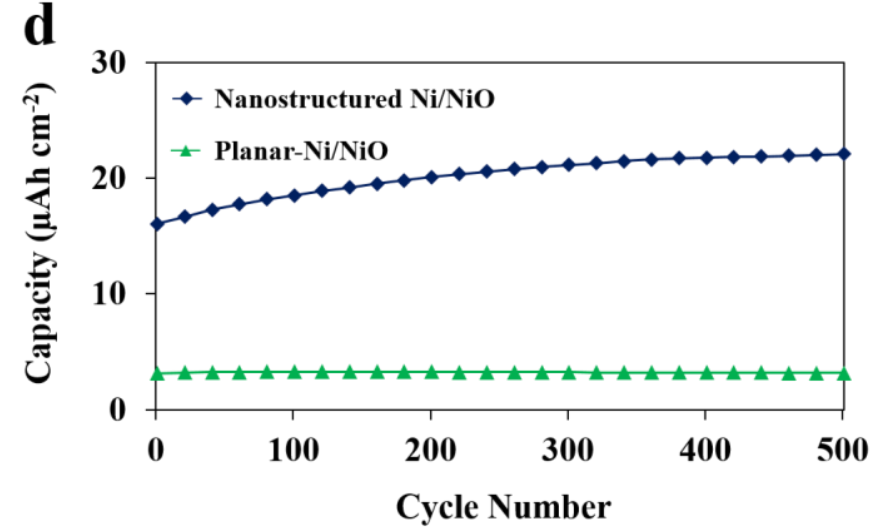

Fig. 8 The Nyquist plots acquired from (a) planar-Ni/NiO and (b) nanostructured $\mathrm{Ni} / \mathrm{NiO}$ during the first 500 galvanostatic charge/discharge at $2 \mathrm{~mA} \mathrm{~cm}^{-2}$. (c) The Randles circuit diagram used for analysis of the Nyquist plots and (d) areal discharge capacity of the nanostructured- and planar-Ni/NiO electrodes over the first 500 cycles acquired along with the EIS measurements. 